\title{
Autonomia e Discricionariedade do Ministério Público no Brasil*
}

\author{
Fábio Kerche
}

\section{INTRODUÇÃO}

$\mathrm{O}$ Ministério Público no Brasil, até a Constituição de 1988, era uma instituição ligada ao Poder Executivo, como é o modelo na maioria das democracias consolidadas. Embora sua previsão constitucional tenha ocupado diferentes seções e capítulos das diversas cartas magnas republicanas, instrumentos institucionais, tais como a indicação e destituição pelo presidente do procurador-geral da República, comprovavam sua ligação com o governo. Os constituintes de 1987/88, contudo, decidiram garantir mais autonomia à Instituição, não somente do ponto de vista formal, fazendo-a constar de capítulo à parte do Poder Executivo, como também criando mecanismos que protegem consideravelmente o Ministério Público dos estados e da União contra ingerências por parte dos governantes em particular e dos políticos de uma maneira geral. Essa autonomia, entretanto, não foi acompanhada por significativos instrumentos de accountability.

Não é somente a autonomia que transforma promotores e procuradores em importantes atores políticos. Autonomia sem instrumentos de

\footnotetext{
*Esta é uma versão modificada do segundo capítulo de minha tese de doutorado-O Ministério Público no Brasil: Autonomia, Organização e Atribuições -, defendida no Departamento de Ciência Política da Universidade de São Paulo - USP, em 2003. Agradeço aos pareceristas anônimos de DADOS por suas valiosas sugestões.
}

DADOS - Revista de Ciências Sociais, Rio de Janeiro, Vol. 50, nํ2, 2007, pp. 259 a 279. 
ação não seria suficiente para que as notícias sobre a atuação do Ministério Público migrassem dos cadernos policiais para os espaços destinados à política nos jornais. O inverso também é verdadeiro: somente instrumentos de ação - tais como ação penal pública, ação civil pública e inquérito civil - sem autonomia transformariam o Ministério Público em instituição do Poder Executivo e executora de decisões e orientações governamentais.

Além disso, o leque de atribuições do Ministério Público é extenso, permitindo afirmar que há poucos assuntos referentes à sociedade brasileira que não possam ser transformados pela instituição em uma questão judicial. De um crime passional ao desvio de dinheiro por parte de um burocrata, passando pela poluição de um rio ou pelo direito de um político se candidatar em uma eleição, quase todos os assuntos podem ser judicializados pela instituição.

Este artigo discutirá o novo Ministério Público surgido pós-Constituição de 1988. A conclusão é que o Ministério Público é singular porque combina elementos - autonomia, instrumentos de ação, discricionariedade e amplo leque de atribuições - que não são comuns em instituições com poucos mecanismos de accountability.

\section{AUTONOMIA DO MINISTÉRIO PÚBLICO}

Os constituintes brasileiros de 1987/88 retiraram o Ministério Público de sua ligação direta com o Poder Executivo sem colocá-lo subordinado ao Poder Legislativo ou ao Judiciário. A autonomia em relação aos poderes de Estado, entretanto, não precisaria significar necessariamente a independência de qualquer tipo de accountability político. A questão é descobrir se há instrumentos, mesmo com a autonomia da instituição, capazes de garantir que promotores e procuradores de justiça prestem contas de suas ações, se são responsivos a um ator externo à organização e se os integrantes do Ministério Público podem ser responsabilizados por seus atos quando identificados desvios.

O número de sanções aplicadas pelos políticos, o número de comissões parlamentares responsáveis por fiscalizar uma instituição, a exigência de relatórios anuais de atividade etc. são os indicadores mais evidentes para avaliar o grau de interferência externa sobre uma organização.

Se o único parâmetro fosse esse tipo de fiscalização a posteriori, conhecida como patrulha de polícia (Kiewiet e McCubbins, 1991), a conclu- 
são seria que há total ausência de accountability e que os constituintes abriram mão de qualquer tipo de interferência sobre os rumos do Ministério Público no Brasil, ocorrendo uma abdicação por parte dos políticos em relação à instituição. As sanções diretas não ocorrem, inclusive porque não existem instrumentos para que os políticos as façam. Embora seja prevista uma fiscalização contábil, financeira, orçamentária, operacional e patrimonial pelo Parlamento, esta se restringe a questões de responsabilidade do Tribunal de Contas e não se traduz no acompanhamento das atividades propriamente processuais do Ministério Público. Nesse sentido, os políticos seriam incapazes de reverter a atuação dos integrantes do Ministério Público pela ausência de instrumentos diretos para esse fim.

Alternativa diversa é buscar instrumentos indiretos que poderiam servir de incentivo para que a instituição observasse os desejos dos políticos. A fiscalização a posteriori de tipo patrulha de polícia é apenas uma das possibilidades - menos eficiente, diga-se de passagem -, mas não a única. Não é porque os políticos não punem constantemente os integrantes do Ministério Público e não fiscalizam diretamente as ações tomadas pelos integrantes da organização que, necessariamente, os promotores não levam em conta o desejo dos políticos e que estes não possam reverter o tipo de atuação do Ministério Público, pelo menos no médio prazo. Essa falta de punição pode indicar, na verdade, que os promotores e procuradores de justiça estão se antecipando aos desejos dos políticos para evitar possíveis sanções. Dito de outra forma,

"[...] o fato de que os agents da burocracia aparentam fazer política pública com pouca orientação direta dos políticos eleitos não significa necessariamente que os burocratas são responsáveis pelas escolhas políticas ou que eles se utilizam de uma significativa discricionariedade. As escolhas realizadas pela burocracia estão fortemente ligadas a um jogo em que o poder de indicação do Executivo e do Legislativo, junto com a ameaça de sanções, proporciona uma influência potencialmente decisiva sobre a política" (Calvert, McCubbins e Weingast, 1989:589, ênfase e tradução do autor).

A delegação de tarefas e poderes por parte dos políticos para uma instituição estatal, portanto, nem sempre é sinônimo de abdicação. Esta significa "que o agent possui a completa discricionariedade sobre as escolhas das políticas públicas e que o principal não detém controle" (McCubbins e Noble, 1995:74, ênfases e tradução do autor). A definição, como os próprios autores reconhecem, é bastante extrema, já que 
poderia haver graus diversos de abdicação, "mas relativas quantidades de abdicação significam que o principal pode influenciar as escolhas do agent em pelo menos alguma dimensão" (ibidem, ênfases e tradução do autor). Desse modo, a abdicação absoluta somente existiria em uma relação entre políticos e burocratas se os primeiros não detivessem nenhum mecanismo para modificar as ações e iniciativas dos atores não-eleitos. Caso haja algum tipo de controle orçamentário e/ou os políticos detenham instrumentos institucionais mesmo que indiretos em relação à burocracia, não é possível caracterizar a transferência de tarefas como uma abdicação.

Por essa definição, órgãos com alto grau de autonomia diante dos políticos não seriam realmente autônomos. Afinal, é prerrogativa dos atores eleitos aprovar o orçamento, mesmo quando proposto pelo próprio órgão. Nessa linha de argumentação, o Ministério Público pós-Constituição de 1988 é muito semelhante ao Ministério Público da ditadura militar - afinal, os orçamentos, em ambos os casos, são aprovados, em última instância, por políticos. Além disso, seria possível argumentar que, como a iniciativa legislativa cabe aos atores eleitos, no limite, os políticos poderiam modificar a legislação para alterar os rumos de um órgão estatal, mesmo em casos em que o orçamento é administrado com relativa autonomia ou em casos em que um órgão possui verbas vinculadas. Essa definição, entretanto, não leva em conta que uma organização que possui previsão constitucional, como o Ministério Público, está mais protegida das ingerências externas do que uma prevista por legislação ordinária. Um órgão, por exemplo, que é obrigado a prestar contas regularmente de suas atividades ao Poder Legislativo é menos autônomo do que uma instituição em que para o principal modificar o "contrato" é necessário emendar a Constituição do país. Já um órgão público que propõe seu orçamento ao Poder Legislativo é mais autônomo relativamente do que aqueles que não detêm esse direito. Ao não identificar essas diferenças, pode-se concluir que praticamente não haveria nenhuma organização com autonomia na estrutura estatal e que as mudanças ocorridas em 1988 em relação ao Ministério Público são, no fundo, irrelevantes.

A sugestão deste artigo é que o conceito de abdicação poderia ser mais útil quando flexibilizado e pensado relativamente a outras organizações, tanto nacionais quanto internacionais, ou quando a aprovação do orçamento pelo Legislativo sofresse restrições que limitassem a interferência dos políticos. O orçamento do Ministério Público, por exem- 
plo, é proposto pelo órgão ao Poder Legislativo, e sua administração é realizada pelo próprio Ministério Público, o que aponta uma diferença importante em relação a outras organizações estatais ou ao próprio Ministério Público antes da Constituição de 1988. Além do mais, como a ação penal pública é monopólio do Ministério Público, diminuir suas verbas pode significar a paralisação de atividade fundamental de enforcement da lei, já que não há outro substituto legal para cumprir a função.

Ou seja, a avaliação de que ocorreu apenas uma delegação é simplificadora no sentido de não identificar a criação de uma série de instrumentos, muitos deles previstos constitucionalmente, que dificultam a intervenção do governo ou do Poder Legislativo nos rumos da organização. Por outro lado, afirmar que houve uma abdicação não explica que a independência orçamentária do Ministério Público, por exemplo, seja apenas relativa. Assim, entre abdicação e delegação, surge um fenômeno intermediário: alto grau de autonomia, embora com alguns poucos instrumentos de accountability. A hipótese deste artigo é que houve, para o caso do Ministério Público construído a partir da Constituição de 1988, uma quasi-abdicação.

\section{Instrumentos Institucionais que Garantem Autonomia}

Cabe, então, perguntar, à luz da literatura, quais seriam os instrumentos capazes de reverter o tipo de atuação dos promotores e procuradores de justiça brasileiros e quais seus problemas?

Um primeiro instrumento é a idéia de múltiplos agents, ou seja, tarefas semelhantes são delegadas a diferentes atores estatais. A idéia é que as mesmas tarefas executadas por agents diversos, embora aumentem os custos de manutenção (folha de pagamento, manutenção de equipamentos etc.), geram competição entre as organizações e "combinada[s] a incentivos adequados, melhora[m] o desempenho" (Przeworski, 1998:56-57). Assim, além de diminuir as chances de que ações não sejam tomadas, permite que sejam comparados os níveis de atuação entre os atores - aspecto difícil em matérias sob responsabilidade do Estado.

O pressuposto é de que os políticos podem punir a organização que não esteja atuando corretamente e premiar aquela que desempenha melhor seu papel - por exemplo, garantindo verbas maiores para a segunda, em detrimento da primeira. Mesmo que ocorra a concorrência 
entre organizações, o Ministério Público pode ser punido somente parcialmente, uma vez que há limitações referentes ao corte de seu orçamento. Além do mais, no caso da ação civil pública, embora outros atores possam lançar mão do mesmo instrumento, o recurso ao inquérito civil e à ação penal pública (muitas vezes utilizados de forma complementar à ação civil) é monopólio dos promotores e procuradores, ou seja, o Ministério Público não detém o monopólio sobre uma série de questões, mas possui instrumentos privilegiados relativamente a outros atores, tornando a competição desigual.

Outro instrumento para buscar gerar responsividade das burocracias públicas é que para cada órgão estatal exista outro com poderes para bloquear as ações do primeiro, garantindo uma fiscalização institucional (Kiewiet e McCubbins, 1991; Przeworski, 1998). O problema de múltiplos agents com capacidade de veto sobre um órgão é que, quanto maior o número de atores com direito a veto, maior a dificuldade de se modificar o status quo; quanto maior o número de mecanismos de controle sobre o agent, maior será a dificuldade de atuação deste para mudanças que justificaram sua criação: "Controles [checks], portanto, inibem a possibilidade que os agents atuem da forma que o principal considera indesejável, mas necessariamente também obstaculizam os agents de atuarem no sentido desejado [...]" (Kiewiet e McCubbins,1991:34, ênfases e tradução do autor).

Um aspecto importante, contudo, é se o Poder Judiciário pode ser incluído como um órgão com poderes para bloquear ações de outros atores estatais, incentivando uma responsividade aos políticos dos atores não-eleitos. Afinal, o Judiciário não responde diretamente aos políticos, e a questão aqui é uma fiscalização institucional entre os agents em que o principal é formado por políticos. Se o Poder Judiciário fosse uma dessas organizações, não haveria nenhum ator estatal realmente autônomo. Mesmo agências de regulação, que gozam de alto grau de autonomia, podem ter suas ações revistas pelo Poder Judiciário. Em outras palavras, o Poder Judiciário não é um agent que participa da fiscalização institucional incentivado por um principal formado por políticos.

Contudo, caso seja incluído o Poder Judiciário como um dos atores com direito a veto sobre o Ministério Público e responsável pelo accountability sobre a instituição, poder-se-ia afirmar que a atuação dos promotores estaria limitada? A resposta a esta pergunta é sim, pelo menos em boa parte dos casos. Afinal, os promotores e procuradores bra- 
sileiros são aqueles que propõem as ações, mas é o Poder Judiciário que as julga. Entretanto, existem tipos de atuação em que o Ministério Público independe dos juízes, embora em um segundo momento os prejudicados possam recorrer aos tribunais:

\begin{abstract}
"Problemas relacionados ao direito do consumidor, ao meio ambiente, à comunidade são, na maior parte das vezes, resolvidos sem o recurso aos procedimentos judiciais que os levariam ao Poder Judiciário. Aliás, promotores e procuradores priorizam a solução a partir de acordos entre as partes em litígio, procedimentos administrativos, requisição de providências aos órgãos públicos e privados e demais instrumentos extrajudiciais. Chega-se a calcular que $90 \%$ das questões são resolvidas sem o recurso ao Judiciário" (Sadek, 2000:28).
\end{abstract}

Além disso, em questões relativas diretamente ao jogo político, a resposta do Poder Judiciário pode vir tarde demais. O trâmite dos processos judiciais dificulta que um político acusado de alguma irregularidade seja julgado a tempo de, por exemplo, ver o seu nome "limpo" antes de uma eleição. Como na maioria dos casos não há impedimentos para o posicionamento público dos promotores sobre políticos acusados de irregularidades, a imprensa é utilizada para levantar suspeitas (e, muitas vezes, proceder ao próprio julgamento) que podem prejudicar os políticos. Mesmo a responsabilização judicial destes promotores por acusações que não se sustentam é uma possibilidade remota e nunca política, distanciando essa punição de um mecanismo claro de $a c$ countability.

Em suma: o Poder Judiciário não é um típico instrumento de indução sobre os promotores para que estes atuem no sentido desejado pelos políticos justamente porque os juízes não respondem aos políticos. $\mathrm{O}$ Judiciário também não é um parâmetro razoável por si só para indicar se uma instituição goza de altas doses de autonomia - afinal, sempre há a possibilidade de se recorrer aos tribunais, o que levaria à conclusão de que nenhum ator estatal é autônomo. Além disso, há uma série de iniciativas do Ministério Público que passam à margem dos juízes ou cujos procedimentos processuais impedem que as respostas cheguem em tempo razoável do ponto de vista do jogo político-eleitoral.

Outro instrumento importante para que os políticos exerçam influência sobre os rumos de um órgão estatal é o direito de indicar o chefe da organização, colocando no cargo alguém afinado com seus interesses. Entretanto, é preciso também que os políticos detenham os mecanis- 
mos para retirar da chefia aqueles que não observam seus desejos. O temor da punição - a perda do cargo - é fundamental para gerar incentivos para que o agent observe os desejos do principal (Shapiro, 1997; Finn, 1993; Calvert, McCubbins e Weingast, 1989). Na busca por se manter no cargo, o agent se antecipa procurando agradar os políticos. Esse instrumento é tão importante que, na análise de agências norte-americanas, Wood e Waterman descobriram que "em cinco dos sete programas examinados, os resultados da agência mudaram imediatamente após troca de chefia" (1991:822, tradução do autor).

No caso da escolha do chefe do Ministério Público da União, o procurador-geral da República é indicado pelo presidente, entre os membros de carreira do Ministério Público da União, sendo que seu nome deve ser aprovado pela maioria do Senado. Essa forma de indicação poderia sugerir que o cargo é de confiança e, portanto, um instrumento importante de interferência dos políticos sobre o Ministério Público da União. Pela lógica aqui descrita, o principal escolheria alguém afinado com seus interesses, e o procurador-geral seria o responsável por criar uma política institucional, respeitando os desejos dos políticos envolvidos no processo de escolha.

Entretanto, dois mecanismos institucionais enfraquecem essa interpretação. O primeiro aspecto é que, ao observar as regras de demissão do ocupante do cargo, se nota que o agent é bastante protegido da interferência dos políticos. Além do mandato de dois anos, o procurador-geral da República somente é passível de demissão por iniciativa do presidente da República, precedida de autorização da maioria absoluta do Senado. Se a demissão de um ministro de Estado, ato decidido somente pelo presidente, em muitos casos, é custosa do ponto de vista político (alianças são rompidas, cargos sugeridos por partidos são perdidos etc.), com a necessidade da participação do Senado, tal iniciativa pode ser extremamente difícil. Essa proteção é uma exceção na política brasileira, tanto em relação à maioria dos cargos na estrutura estatal quanto em relação às outras constituições, no que se refere ao Ministério Público. Mesmo em perspectiva comparada, geralmente, o chefe da instituição que detém o monopólio da ação penal é indicado e destituído pela exclusiva vontade do chefe do Poder Executivo ${ }^{1}$.

A proteção contra a exoneração decidida exclusivamente pelo presidente não é desfrutada no Brasil nem pelo presidente do Banco Central nem por diretores de empresas estatais, por exemplo. A relação com o 
principal, além de frágil, também é baseada em dois principals distintos, já que não há garantias de que o presidente tenha maioria no Senado. Segundo Kiewiet e McCubbins (1991), múltiplos principals podem não conseguir expressar uma única política, o que dificultaria a avaliação da atuação dos agents e garantiria certa margem de manobra para os burocratas, podendo gerar ações prejudiciais aos interesses de um dos principals $^{2}$. Afinal, como há dois principals, não fica claro qual deles o agent deve levar em conta para orientar sua atuação, já que nem sempre os interesses são coincidentes.

Além disso, outro dado limita a importância de se indicar o procurador-geral da República. Os instrumentos institucionais para que o procurador-geral exerça controle em relação aos demais integrantes do Ministério Público da União também são limitados quando aquele é transformado em principal. A estrutura do Ministério Público não é tradicionalmente hierárquica, como se dá na maior parte das organizações estatais. Os procuradores do Ministério Público Federal possuem considerável autonomia diante do procurador-geral da República, assim como os promotores em relação aos procuradores-gerais de Justiça dos estados. As promoções dos membros do Ministério Público, que poderiam funcionar como um importante instrumento de incentivo para um alinhamento dos promotores com o procurador-geral, ocorrem independentemente da vontade do chefe da instituição, sendo definidas ora pelo critério de antiguidade, ora por decisão de órgãos colegiados do Ministério Público. Em outras palavras, mesmo que o promotor tenha um desempenho profissional não afinado com as orientações do procurador-geral, há mecanismos institucionais que garantem o progresso em sua carreira. Esse modelo pode incentivar uma baixa previsibilidade de atuação do Ministério Público e impossibilitar a criação de uma política institucional unificada e coerente definida pelo procurador-geral.

A possibilidade de recondução ao cargo, embora limitada pela questão dos múltiplos principals, poderia servir como incentivo para que o procurador-geral da República levasse em consideração os desejos dos políticos. Pela Constituição, o procurador-geral da República pode ser reconduzido quantas vezes o presidente e o Senado acharem conveniente. Assim, buscando manter-se no cargo, o procurador-geral atenderia aos interesses dos principals com vistas a garantir sua recondução. É a lógica do voto de accountability transposta para o caso de um sistema sem eleição direta ${ }^{3}$. Entretanto, com um presidente sem maioria no Se- 
nado, a quem o procurador-geral deveria "agradar"? Caso seja ao presidente, o procurador-geral pode ser vetado no Senado. Caso seja aos senadores, o procurador pode não ser indicado pelo presidente.

Situação pouco diversa é a indicação e a destituição dos procuradores-gerais de Justiça, chefes dos Ministérios Públicos estaduais. Pelas regras institucionais, por meio de eleição direta entre os membros da instituição, são selecionados três nomes que serão apresentados ao governador do Estado. Assim como o procurador-geral da República, o procurador-geral de Justiça também possui um mandato de dois anos, podendo somente ser afastado do cargo por decisão da maioria absoluta do Poder Legislativo estadual, sem a necessidade de interferência do governador.

Nesse caso, portanto, os principals são múltiplos: os próprios colegas da instituição estadual, que votam para compor a lista tríplice; o governador, que escolhe entre os três nomes apresentados; e os deputados estaduais, que podem decidir pelo afastamento do procurador-geral de Justiça. Mas outro detalhe merece destaque. Diferentemente do procurador-geral da República, o procurador-geral de Justiça só pode ser reconduzido ao cargo uma única vez, transformando o processo em algo ainda mais imprevisível. Em uma eleição direta, o partido político tem um papel importante no caso de candidatos que se apresentem pela primeira vez aos eleitores, assim como em casos de uma última candidatura. Na ausência de partidos, políticos que não continuassem na vida pública teriam menos incentivos para observar os desejos dos seus eleitores, já que não disputariam novas eleições nem transfeririam seu legado a um partido político. Transpondo esse modelo para o caso de um procurador-geral de Justiça, que tem um número de oportunidades finito (uma recondução) e nenhuma agremiação partidária, este poderia tornar-se "incontrolável" em seu segundo mandato.

Em outras palavras, embora a indicação daquele que ocupa a chefia de uma organização seja um instrumento importante para garantir a influência dos políticos sobre uma instituição estatal, isto pode não ocorrer no caso do Ministério Público no Brasil. Primeiro, porque não há um único principal. Segundo, porque o cargo não é propriamente de confiança. Terceiro, a organização não é tradicionalmente hierárquica, sendo que o chefe da organização tem poderes internos bastante limitados. 
Outro instrumento capaz de gerar incentivos para que atores não-eleitos atuem no sentido desejado pelos políticos é o alarme de incêndio (Kiewiet e McCubbins, 1991). Como a fiscalização a posteriori, do tipo patrulha de polícia, não é capaz de garantir que o agent relate a verdade sobre sua atuação, a fiscalização do tipo alarme de incêndio busca informações naqueles que recebem os serviços da burocracia, ou seja, os cidadãos.

"[...] precisamente pelo fato de a burocracia estatal prestar serviços aos cidadãos, são os cidadãos que têm a melhor informação sobre seu desempenho. Além disso, se os políticos se preocupam com o bem-estar dos cidadãos, então os interesses dos cidadãos coincidem com os interesses dos políticos, que são os principals, e não com os interesses dos burocratas que são os agents" (Przeworski, 1998:58).

O alarme de incêndio, portanto, permite que os políticos busquem modificar a atuação dos agents quando os grupos organizados, que giram na órbita daquela burocracia, fazem soar o alarme contra eventuais falhas daqueles atores estatais. O problema desse alarme é que, quando os grupos não são organizados, estes podem não se fazer ouvir pelos políticos, ou, utilizando um termo apresentado em Moe (1984), o decibel meter não funciona a contento. Outra dificuldade é que, se os políticos não possuem mecanismos institucionais para modificar a atuação de seus agents, mesmo em caso de disparo do alarme, não há como corrigir rapidamente a atuação da burocracia.

O alarme de incêndio seria um instrumento importante para a fiscalização do Ministério Público, já que, por exemplo, não há a apresentação de uma prestação de contas aos políticos sobre a atuação dos promotores - mesmo sabendo que isso não significa que os agents não esconderão informações de seu principal. O problema, contudo, é que a atuação do Ministério Público nem sempre é voltada para grupos organizados, mas muitas vezes para indivíduos isolados entre si ou grupos dispersos. Assim, o alarme pode soar fraco e não ser ouvido pelos políticos. Mesmo que seja ouvido, quais são os instrumentos políticos para punir a instituição por eventuais desvios? A questão é que os mecanismos institucionais de fiscalização sobre a organização, além de imperfeitos, praticamente não deixam margem para punições, dificultando, portanto, o accountability.

Uma medida que poderia limitar a autonomia do Ministério Público foi a criação do Conselho Nacional do Ministério Público em 2005. O 
órgão é composto pelo procurador-geral da República, quatro membros do Ministério Público da União, três membros do Ministério Público dos estados, dois juízes indicados pelo Supremo Tribunal Federal e outro pelo Superior Tribunal de Justiça, dois advogados indicados pela Ordem dos Advogados do Brasil e dois cidadãos de notável saber jurídico e reputação ilibada indicados pela Câmara dos Deputados e pelo Senado Federal. Sua atribuição é a fiscalização da gestão administrativa e financeira do Ministério Público, o controle da atuação dos promotores e procuradores de Justiça e a escolha de um corregedor nacional entre os membros que o integram. Embora essa iniciativa indique um maior accountability em relação à organização, e demonstre que os políticos não abdicaram de seu direito de legislar com vistas a influenciar a atuação do Ministério Público, vale notar que os membros do órgão são exclusivamente operadores do direito, que a maioria é composta por integrantes do próprio Ministério Público e que somente dois deles são indicados diretamente por parlamentares eleitos pelo voto direto dos cidadãos. Não há dados suficientes para afirmações definitivas sobre a atuação do Conselho. Entretanto, se a idéia era uma fiscalização externa mais efetiva e cotidiana, a composição do órgão com a maioria de membros do próprio Ministério Público pode não ser suficiente para romper elementos corporativos.

Assim, a conclusão é que houve, senão uma abdicação completa (porque os políticos ainda podem emendar a Constituição, modificar a legislação infraconstitucional ou interferir no orçamento proposto pelo Ministério Público), pelo menos uma delegação que garantiu boa margem de autonomia e uma amplitude de tarefas pouco comuns a órgãos estatais com integrantes não-eleitos. Em outras palavras, houve uma quasi-abdicação.

\section{AMPLO LEQUE DE ATRIBUIÇÕES E INSTRUMENTOS DE AÇÃO}

Esta quasi-abdicação, embora pouco comum ao princípio de que em uma democracia o poder soberano é exercido pelos cidadãos por meio de seus representantes eleitos, é identificável em alguns casos, não sendo exclusividade do Ministério Público no Brasil. Alguns órgãos, como o Banco Central norte-americano, os ombudsmen nórdicos ou as agências reguladoras brasileiras, detêm suficiente autonomia perante os políticos ou a própria sociedade. Em alguns casos, altas doses de independência podem até ser, se não desejáveis do ponto de vista do sistema baseado na soberania popular, pelo menos aceitáveis: ou porque 
garantem liberdade aos atores para agirem contrariamente aos interesses políticos partidários momentâneos, ou porque garantem aos compromissos políticos maior credibilidade, não aparecendo como conseqüência direta do desejo de algum grupo político partidário localizado, ou porque, ainda, diminuem os custos de transação do Legislativo.

Entretanto, nem toda quasi-abdicação é igual no que se refere à amplitude das tarefas transferidas para os atores não-eleitos. Pode-se afirmar que os exemplos de órgãos com maciça autonomia são geralmente aqueles que desempenham papéis pontuais em suas interferências no jogo político, na sociedade, na economia ou nas políticas públicas. Afinal, é mais fácil prever regras legais e mecanismos institucionais aos burocratas quando suas funções são bem delimitadas e com pouca discricionariedade. Em contrapartida, quanto maior o leque de atribuições e mais vaga a legislação - aumentando a chance de discricionariedade dos atores não-eleitos -, maior deve ser o accountability para que o principal possa acompanhar o desempenho de seu agent. Segundo Shapiro: “Uma coisa [...] de qualquer modo, é colocar as políticas públicas para além do controle democrático de acordo com as relativamente fixas cláusulas da constituição e outra completamente diferente é colocá-las nas mãos de uma agência de governo com um poder discricionário" (1997:289, tradução do autor). Desse modo, quando se limita o grau de discricionariedade, as chances de arbitrariedades também diminuem, tornando mais razoável em uma democracia a existência de órgãos com altas doses de autonomia. Por outro lado, quanto maior a liberdade de um ator estatal, maior deve ser a fiscalização sobre sua atuação.

Partindo da observação de que o Ministério Público brasileiro sofreu um processo de quasi-abdicação, pode-se afirmar que essas recomendações normativas, relativas à limitação de tarefas e limitação de discricionariedade, são cumpridas em relação à organização? A resposta varia de acordo com a função observada. Como se sabe, o Ministério Público é, na verdade, uma instituição única que desempenha papéis diversos. Ao ser observado o papel "clássico" do Ministério Público, ou seja, a responsabilidade de propor a ação penal pública para crimes comuns, pode-se afirmar, como será demonstrado, que o grau de discricionariedade é relativamente baixo. Entretanto, em relação às duas outras funções principais - a fiscalização de políticos e burocratas (um papel semelhante ao dos ombudsmen) e a fiscalização do cumprimento da lei pelos governos e por particulares -, tais recomendações não são 
cumpridas, garantindo aos promotores e procuradores altas doses de discricionariedade com pouco accountability.

\section{O Papel Tradicional: Condução da Ação Penal Pública}

Quando ocorre um crime - roubo ou assassinato, por exemplo -, a polícia é responsável pela investigação. Sob a coordenação do delegado, o inquérito policial é elaborado e enviado para um juiz, que distribui o caso para o promotor responsável. Baseado nessa peça, o promotor vai ao Poder Judiciário, que decidirá sobre a condenação ou absolvição do acusado.

O que obriga o promotor a levar todos os casos ao Poder Judiciário, independentemente da gravidade do mesmo, é o chamado princípio da legalidade, modelo não utilizado em todos os países. Nos Estados Unidos, por exemplo, o promotor pode negociar com o réu a denúncia dos comparsas em troca da diminuição da pena sem a participação do Poder Judiciário, utilizando-se do princípio da oportunidade. Entretanto, em 45 dos 50 estados norte-americanos, os district attorneys são eleitos diretamente pelo voto popular, em um claro mecanismo de accountability vertical. Em outros países que garantem discricionariedade aos seus promotores, geralmente, a agência responsável pela ação penal é ligada ao Ministério da Justiça, sendo o ministro que indica os cargos-chave da instituição, traça estratégias coletivas e possui instrumentos de punição àqueles que se desviam de suas orientações, criando uma política institucional coerente e unificada, em um claro mecanismo de accountability horizontal. No caso brasileiro, em relação à ação penal para crimes comuns, os promotores não possuem discricionariedade para decidir se uma ação deve ou não ser levada ao Judiciário, compensando, até certo ponto, os frágeis instrumentos de $a c$ countability.

Assim, a regra parece se confirmar em relação ao Ministério Público brasileiro: quanto menor o accountability, menor a discricionariedade, sendo que nos países que se orientam pelo princípio da oportunidade a relação é inversa, ou seja, maior discricionariedade combinada com maior accountability. Neste caso específico, a quasi-abdicação em relação ao Ministério Público no Brasil é menos estranha à democracia, pois garante pouca discricionariedade aos promotores e procuradores em relação à ação penal para crimes comuns. 


\section{Processando (ou não) Políticos: Uma Agência de Accountability}

Um órgão responsável pela fiscalização de políticos, como o Ministério Público, é o reconhecimento de que somente os clássicos instrumentos dos checks and balances - poderes de Estado limitando poderes de Estado - não seriam suficientes. A complexidade do Estado contemporâneo fez surgir órgãos especializados e auxiliares dos poderes de Estado, não previstos na teoria clássica da democracia liberal, para limitar abusos de atores estatais - como as ouvidorias dos países latinos ou os ombudsmen dos países nórdicos, por exemplo. Portanto, um órgão responsável pela fiscalização de políticos não é uma exclusividade brasileira; o que é diferenciado, entre outros, é o grau de independência de todos os seus integrantes e o seu amplo leque de atribuições.

Por outro lado, esse tipo de órgão é também o reconhecimento de que o voto dos eleitores é um instrumento fraco diante da complexidade do jogo político. A fiscalização requer um tal nível de informações que, sem o auxílio de órgãos de accountability, como afirmam Przeworski, Stokes e Manin (1999), o eleitor seria incapaz de controlar seus políticos. Entretanto, há uma diferença entre órgãos que aumentam as informações dos eleitores e os que detêm instrumentos para também processar políticos, ou seja, há uma diferença entre o ombudsman e o Ministério Público brasileiro. Enquanto o primeiro levanta informações para os eleitores ou para os órgãos do Poder Executivo que poderão atuar judicialmente, o Ministério Público no Brasil detém a capacidade, praticamente, sem a necessidade de consultar outro ator, de levar os políticos ao banco dos réus.

A importância e a necessidade de organizações como instrumento de accountability sobre os políticos não é capaz, por si só, de invalidar possíveis críticas. Investigações de homens públicos também podem ser conduzidas de maneira a privilegiar aliados ou prejudicar desafetos, principalmente com o grau de discricionariedade do Ministério Público em relação à ação civil. Mesmo com a participação de políticos nos processos de investigação, como as Comissões Parlamentares de Inquérito - CPIs, os promotores não são obrigados a processar os nomes sugeridos pelos parlamentares. Desse modo, verifica-se uma estranha equação para o processo democrático: um órgão com poucos mecanismos de accountability, mas com razoável grau de discricionariedade. 
Os pontos contrários a essas ressalvas são alguns números de ações contra políticos apresentados por ministérios públicos estaduais. Dos 645 municípios de São Paulo, por exemplo, até o ano 2000,38\% tiveram seus prefeitos processados (Arantes, 2002), um número bastante expressivo. Contudo, há de se observar outro aspecto: se o Ministério Público detém razoável grau de discricionariedade nas ações civis, ou seja, se a organização pode selecionar casos, ao processar mais de duas centenas de prefeitos em um Estado, isto significa que os outros são inocentes? A qual conclusão devemos chegar quando um prefeito não é processado? Pode-se concluir que o Ministério Público deu um certificado de idoneidade ao político, ou que há uma seleção de casos mais importantes que o dele, ou que o promotor é um tipo mais "burocráti-

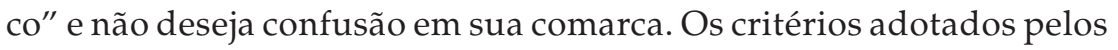
integrantes do Ministério Público, que detém poder discricionário, podem não ser claros. Como afirma William West, citando Kenneth Davis, “Geralmente as mais importantes decisões discricionárias são as negativas, como não iniciar, não investigar, não processar, não entrar em acordo, e as decisões negativas geralmente significam uma disposição definitiva" (West, 1995:25, tradução do autor).

Por fim, outro aspecto deve ser ressaltado. Como a condenação por corrupção no Poder Judiciário é bastante complexa, parece que atuar extrajudicialmente constitui uma espécie de estratégia do Ministério Público ou, pelo menos, de uma parte dele. Ao divulgar à imprensa que está investigando um político, este pode ser condenado pela opinião pública sem um julgamento baseado no princípio liberal de que todos são inocentes até que se prove o contrário. Imagine-se uma situação-limite: uma semana antes das eleições, um promotor ou procurador anuncia à imprensa que determinado candidato é suspeito do desvio de dinheiro quando ocupava um cargo na administração pública. Quais são as chances de defesa deste candidato?

\section{Defensor Discricionário de Direitos: A Ação Civil Pública}

Outra importante atribuição dos promotores e procuradores brasileiros refere-se à fiscalização do correto cumprimento da lei, incluindo-se aí as leis constitucionais. O principal instrumento para essa tarefa é a ação civil pública e o inquérito civil.

A ação civil pública é um instrumento jurídico que permite a representação, junto ao Poder Judiciário, de interesses coletivos, difusos e indi- 
viduais homogêneos ${ }^{4}$. União, estados, municípios, autarquias, empresas públicas, fundações, sociedades de economia mista e associações existentes há pelo menos um ano, com objetivos de defesa do meio ambiente, do consumidor ou do patrimônio histórico e cultural, e Ministério Público podem lançar mão de tal mecanismo. Por esse motivo, mesmo que a ação civil esteja prevista constitucionalmente na seção destinada ao Ministério Público, ela não é monopólio da instituição, embora responda por $90 \%$ das ações, segundo Ada Pelegrine Grinover (Sadek, 1997). Portanto, o Ministério Público é o ator privilegiado para utilizar este instrumento que permite judicializar uma gama imensa de assuntos e que garante a discricionariedade aos integrantes da instituição.

A discricionariedade é reforçada por meio do monopólio do inquérito civil pelo Ministério Público - instrumento utilizado na fase preliminar ao processo judicial. O inquérito civil permite que as investigações sejam conduzidas e coordenadas pelos promotores, sendo que eles podem decidir independentemente de outro ator estatal se o caso merece se transformar em uma ação civil pública. Ou seja, mesmo não detendo o monopólio sobre a ação civil pública, o Ministério Público é reconhecidamente o mais importante ator a utilizá-la e mantém um alto grau de discricionariedade sobre este ponto. Portanto, um dos elementos que formalmente serviam de defesa contra a falta de instrumentos de accountability (a obrigatoriedade de levar o caso à Justiça como na ação penal e, conseqüentemente, a pouca discricionariedade) perde sua força, garantindo a um órgão com integrantes não-eleitos, muito pouco accountable, o papel de decidir ou não sobre a procedência de um caso.

A argumentação de que a defesa de certos interesses pelos promotores por meio da ação civil coincide com a vontade do cidadão não significa que estes controlem a instituição. Como afirma Gruber, "se por uma feliz coincidência burocratas agem no sentido em que os cidadãos desejam que eles ajam, a burocracia pode parecer não ser um problema tão grande, mas não está sob controle democrático". Isto porque

"Controle deveria ocorrer por meio de um processo de reações antecipadas. Se os burocratas antecipassem com precisão o que os cidadãos gostariam que fosse feito, e então se sentissem constrangidos a agir baseados nesta antecipação, uma forma de controle democrático teria ocorrido. Mas se os burocratas estiverem errados na sua antecipação e agirem em um sentido em que os cidadãos e o legislativo não aprovem, não se pode dizer que suas ações foram controladas pelos cidadãos" (1987:12-13, tradução do autor). 
É possível argumentar que os promotores, em relação ao seu papel na ação civil pública, só estariam cumprindo a lei e, portanto, não interferindo motivados por uma opção política de seus integrantes, mas sim, para garantir o cumprimento do que está previsto constitucionalmente - principalmente em um país onde a sociedade seria incapaz de exigir seus direitos por conta própria. Nesse sentido, haveria uma optimal policy definida constitucionalmente, o que justificaria a existência de um órgão com integrantes não-eleitos, com poderes ampliados e com independência em relação ao jogo político-partidário.

Embora os princípios constitucionais possam ser definidos como objetivos a serem perseguidos, como chegar a eles e quais são as prioridades são questões passíveis de discussão e de discricionariedade dos políticos - e não de burocratas. Em outras palavras, se a lógica das eleições fosse levada ao extremo, todo político buscaria maximizar os ganhos da sociedade através de políticas públicas, não por altruísmo, mas sim porque garantiria a reeleição agradando a todos os eleitores. No entanto, são as limitações orçamentárias que impedem a completa realização dessa opção racional, aspecto que não necessariamente entra no leque de preocupações dos integrantes do Ministério Público brasileiro. Ou seja, na democracia, a escolha de prioridades é realizada por políticos eleitos diretamente pelos cidadãos. Quando essa escolha é feita não pelo embate político, mas transformada em questão jurídica ou técnica, perde-se uma dimensão importante da participação e interferência popular. Assim, a judicialização da política - a transformação de questões tradicionalmente tratadas pelos Poderes Executivo e Legislativo em ações judiciais - caminha juntamente com a negação da política presente nos discursos que desconfiam de partidos e políticos e depositam fé nos técnicos de bancos centrais, agências reguladoras e toda a sorte de instituições com pouca possibilidade de interferência da soberania popular.

\section{CONSIDERAÇÕES FINAIS}

Afirmar que houve uma abdicação dos políticos em relação ao Ministério Público na Constituição de 1988 é desconsiderar instrumentos institucionais importantes. Alguns mecanismos indiretos foram mantidos, dentro da lógica do checks and balances dos estados democráticos. Entretanto, o novo Ministério Público é razoavelmente protegido de injunções político-partidárias mais cotidianas sobre a organização. A 
conclusão é que estamos diante de uma quasi-abdicação dos políticos, pouco comum quando se observa outros órgãos estatais no Brasil.

Essa quasi-abdicação, por si só, não é fenômeno singular em perspectiva comparada, até porque é possível identificar organizações de diversos países também razoavelmente protegidas contra injunções político-partidárias. O que diferencia o Ministério Público brasileiro é que, paralelamente à sua autonomia, os constituintes garantiram razoáveis graus de discricionariedade a estes atores não-eleitos do Estado. Assim, o argumento de que os promotores e procuradores somente cumprem a lei, não precisando, por este motivo, de instrumentos de accountability, não se sustenta. É a possibilidade de exercer a discricionariedade, somada à autonomia, aos instrumentos de ação e ao amplo leque de atribuições, que transforma o Ministério Público em uma organização pouco comum à democracia.

(Recebido para publicação em abril de 2006)

(Versão definitiva em julho de 2007)

\section{NOTAS}

1. Sobre um estudo comparando o Ministério Público no Brasil com seus similares em outras democracias, ver Kerche (2005).

2. Este problema é chamado de Dilema de Madison (Kiewiet e McCubbins, 1991).

3. O voto de accountability é aquele em que o eleitor pune ou premia o candidato de acordo com sua atuação passada. Este tipo de voto é distinto do voto mandate, em que o eleitor seleciona as melhores propostas durante a campanha. Para mais detalhes ver Przeworski, Stokes e Manin (1999), principalmente a introdução.

4. Os interesses difusos e coletivos são os "transindividuais de natureza indivisível" (Arantes, 1999:88), e os individuais homogêneos "são os decorrentes de origem comum" (ibidem). O fato é que os interesses são amplos, tornando possível judicializar praticamente qualquer assunto que envolva um grupo de cidadãos. Para mais detalhes, ver Arantes (1999). 


\section{REFERÊNCIAS BIBLIOGRÁFICAS}

ARANTES, Rogério. (1999), "Direito e Política: O Ministério Público e a Defesa dos Direitos Coletivos". Revista Brasileira de Ciências Sociais, vol. 14, no 39, pp. 83-102. . (2002), Ministério Público e Política no Brasil. São Paulo, Educ/Sumaré/Fapesp.

CALVERT, Randall L., McCUBBINS, Mathew D. e WEINGAST, Barry R. (1989), “A Theory of Political Control and Agency Discretion". American Journal of Political Science, vol. 33, no 3, pp. 588-611.

FINN, T. D’Arcy. (1993), “Independent Review Agencies and Accountability: Snapping at the Heels of Government". Optimum: The Journal of Public Sector Management, vol. 24, ำ 2 .

GRUBER, Judith E. (1987), Controlling Bureaucracies: Dilemmas in Democratic Governance. Berkeley/Los Angeles/London, University of California Press.

KERCHE, Fábio. (2005), “Agências Responsáveis pela Ação Penal: Um Estudo Comparativo". Revista Brasileira de Ciências Criminais, no 55, pp. 127-152.

KIEWIET, D. Roderick e McCUBBINS, Mathew D. (1991), The Logic of Delegation: Congressional Parties and the Appropriations Process. Chicago, University of Chicago Press.

McCUBBINS, Mathew e NOBLE, Gregory. (1995), "Equilibrium Behavior and the Appearance of Power: Legislators, Bureaucrats and the Budget Process in the U.S. and Japan", in P. Cowhey e M. McCubbins (eds.), Structure and Policy in Japan and the United States. New York, Cambridge University Press.

MOE, Terry M. (1984), “The New Economics of Organization”. American Journal of Political Science, vol. 28, no 4, pp. 739-777.

PRZEWORSKI, Adam. (1998), “Sobre o Desenho Institucional do Estado: Uma Perspectiva Agent x Principal", in B. Pereira (org.), Reforma do Estado e Administração Pública Gerencial. Rio de Janeiro, Editora FGV.

STOKES, Susan e MANIN, Bernard (eds.). (1999), Democracy, Accountability and Representation. Cambridge, Cambridge University Press.

SADEK, Maria Tereza (org.). (1997), O Ministério Público e a Justiça no Brasil. São Paulo, Idesp/Sumaré.

(2000), “Cidadania e Ministério Público", in M. T. Sadek (org.), Justiça e Cidadania no Brasil. São Paulo, Sumaré.

SHAPIRO, Martin. (1997), "The Problems of Independent Agencies in the United States and the European Union". Journal of European Public Policy, vol. 4, no2, pp. 276-277.

WEST, William F. (1995), Controlling the Bureaucracy: Institutional Constraints in Theory and Practice. Armonk/London, M. E. Sharp.

WOOD, B. Dan e WATERMAN, Richard W. (1991), “The Dynamics of Political Control of the Bureaucracy". The American Political Science Review, vol. 85, no 3, pp. 801-828. 


\title{
ABSTRACT \\ Autonomy and Discretionary Power of the Public Prosecutor's Office in Brazil
}

This article deals with the autonomy, discretionary power, and wide range of attributions allotted to the Public Prosecutor's Office in Brazil by the 1988 Constitution. One of the objectives is to analyze whether this combination is not alien to the democratic principle that state institutions, and even those that do not choose their members by direct elections, should be accountable to the public for their acts. The author draws on the neo-institutionalist literature on bureaucracy to analyze the Public Prosecutor's Office in Brazil. The conclusion is that there has been a quasi-abdication by politicians in relation to the institution in question, a rare occurrence in Brazil and in other democracies.

Key words: Public Prosecutor's Office; accountability; democracy

\begin{abstract}
RÉSUMÉ
Autonomie et Pouvoir Discrétionnaire du Ministère Public au Brésil

Dans cet article, on examine l'autonomie, le pouvoir discrétionnaire et le large éventail d'attributions du Ministère Public au Brésil figurant dans la Constitution de 1988, afin de savoir si cet assemblage ne s'oppose pas au principe démocratique selon lequel les institutions d'État, y compris celles qui n'utilisent pas le système d'élections directes pour l'admission de leurs membres, doivent rendre compte de leurs actes devant le peuple souverain. Dans ce but, on part de la littérature néo-institutionnelle concernant la bureaucratie afin d'étudier le Ministère Public au Brésil. En conclusion, on voit que les hommes politiques se servent très peu de l'institution, ce qui est plutôt rare au Brésil ainsi que chez d'autres pays démocratiques.
\end{abstract}

Mots-clé: Ministère Public; accountability; démocratie 